\title{
COMPARING CITIES OF THE WORLD ACCORDING TO THEIR FOOD SECURITY RISKS AND OPPORTUNITIES
}

\author{
WIL H.G.J. HENNEN, VASCO DIOGO, NICO B.P. POLMAN \& MARIJKE W.C. DIJKSHOORN-DEKKER \\ Wageningen Economic Research (WUR), The Hague, The Netherlands
}

\begin{abstract}
Due to the combined effect of climate change, expected population growth and increased concentration of population in cities and towns, food insecurity in urban areas is becoming of increasing concern and is regarded as one of the most prominent development challenges for the 21 st century. Cities differ with respect to their specific food security risks and opportunities of local food supply to meet the increasing demand for food. The tool "Global Metropolitan Detector" has been developed to compare cities of the world based on different dimensions of food security, particularly availability, accessibility, and affordability of food, risk of floods and climate change, and healthy diets. Worldwide publicly available datasets, e.g. from FAOSTAT, EarthStat and WorldClim, are used. These are separately converted (aggregated/disaggregated) to a homogenous 5 arc-minute grid and combined in the tool to calculate (by weighted average) and compare the demand and local supply of food, including the required area of land to meet the city-specific consumption needs (measured in "Food Metres"). The purpose is to benchmark 850 cities based on several aspects related to food security. The resulting benchmark of cities and their indicator values can be visualised in maps showing their position with respect to food security in general, or investigate particular aspects in more detail, e.g. cities having low/high flood risks or cities that are better able to meet the demand of (fresh) vegetables and fruit from local producers. The maps can support policymakers to identify causes and locations of food insecurity, and the indicative results - based on limited available worldwide data - can serve as an inducement for further investigation with more detailed data from cities.
\end{abstract}

Keywords: metropolitan, benchmarking, cities, urban, food secure, food metres, FAO, GIS, climate.

\section{INTRODUCTION}

Food security is defined as a situation in which "all people, at all times, have physical and economic access to sufficient, safe and nutritious food to meet their dietary needs and food preferences for an active and healthy life" [1], [2]. Given that the trade of food commodities is nowadays possible at reasonably low cost, food security is not only about whether food is "available," but also whether the monetary and nonmonetary resources at the disposal of the population are sufficient to allow everyone access to adequate quantities of food [3]. Food security is thus comprised of four key dimensions [3]-[5]:

- Availability: the overall ability of the agricultural system to meet food demand, including the agro-climatic conditions affecting crop and pasture production and the socio-economic and cultural factors determining where and how farmers respond to markets.

- Stability: the extent to which there is a risk of temporarily or permanently losing access to the resources needed to consume adequate food.

- Accessibility: the access to adequate resources, given existing political, economic and social conditions, to acquire appropriate food for a nutritious diet.

- Utilization: the food safety and quality aspects related to nutrition and health, including the sanitary conditions across the entire food chain. 
Numerous measures have been developed to quantify the overall status and the regional variability of food security. Covering all dimensions of food security in a single measure is, however, challenging. For example, FAO's indicator of undernourishment [2] is a widely used measure of food security that has the advantage of relying on a relatively straightforward methodology and readily available data [3]. However, it only covers two dimensions of food security, availability and accessibility. The Global Food Security Index (GFSI) was developed with the aim of creating a common framework for measuring the risks and benchmark a country's food security, while simultaneously addressing the issues of affordability, availability and utilization in 113 countries around the world [6]. However, a large number of indicators used in GFSI composite index rely on authors' own expert knowledge and data sources that are not readily available to the public. Furthermore, the GFSI focus at the country level does not allow to identify existing regional disparities within countries, which can be quite significant as hunger and malnutrition issues tend to be concentrated in low income inner-city neighborhoods, large metropolitan regions, and remote rural regions [7].

Historically, the global food security policy agenda has been predominantly rural and "productionist" in its orientation [8], based on the premise that food insecurity is primarily a rural problem that should be addressed through an increase of smallholder production [9]. However, food insecurity is becoming an increasing concern for urban populations. Although food is often more plentiful and diverse in the urban areas, it is far from being uniformly accessible to all citizens, as evidenced by the 2008's world food price crisis [10]. Poor urban dwellers are largely net food buyers that depend on markets for their food supplies, thus being particularly vulnerable to food price shocks [11]. Household income and the cost of food are critical determinants of food security, but high living costs in the city associated with housing, transport and social services also put additional pressure on the ability of the chronically poor to access sufficient food [9]. Ruel and Garrett [12] found that in several African countries at least $40 \%$ of the urban population is calorie deficient, up to $90 \%$ in Ethiopia.

World population is expected to grow by 2.5 billion between 2015 and 2050, with the proportion of people living in towns and cities being expected to increase from $54 \%$ to $66 \%$ [13]. Increased urbanization will imply that household agriculture will become less significant as a primary food source. Furthermore, climate change and increased frequency of extreme events will certainly pose additional challenges to food security, being expected to disproportionately affect low-income households and communities in the cities with the least capacity for adaptation [14]. Hence, urban food security is increasingly regarded as one of the most prominent development challenges for the 21st century [9], [14]-[17].

In this article, we propose an approach to assess and benchmark the state of food security in several cities around the world, given their current conditions and expected future developments. We combine spatially-explicit data on local characteristics, demographic projections at the city level and national level statistics on macro-economic conditions to compute indicators that capture the different dimensions of food security operating in cities at various levels. The proposed benchmarking has the following characteristics:

- covers as many dimensions of food security as possible;

- the underlying methodology is straightforward and transparent;

- the required parameters and data needed are readily and publicly available.

The paper is structured as follows. Firstly, the methodology to assess and benchmark urban food security is outlined in Section 2. Examples of results comparing urban food 
security in cities of different parts of the world are presented in Section 3, followed by a discussion and final conclusions in Section 4.

\section{METHODOLOGY: THE GLOBAL METROPOLITAN DETECTOR}

The Global Metropolitan Detector tool is an extension of the Global-Detector tool, a knowledge-based Geographic Information System (GIS) in $\mathrm{R}$ that aims to detect the worldwide potential for production, demand and market strategies regarding agricultural commodities [18]. It does so by arithmetically combining and weighing public available worldwide GIS data on factors affecting the production and consumption of agricultural commodities. At any spot on the world, i.e. a grid of $5^{\prime} \times 5^{\prime}$ or about $10 \times 10 \mathrm{~km}$, GlobalDetector can show the values from a large amount of indicators, such as temperature, infrastructure, and land characteristics. For urban food security risks, relevant indicators from the library of indicators are chosen based on literature research on food security. For this purpose, the knowledge from different experts is applied to combine these relevant indicators to create potential production maps. For each case of Global-Detector a knowledge-base is developed containing a set of arithmetic procedures that prescribe how to combine the indicators that are chosen by the expert. Different arithmetic procedures can also be chosen by the experts, for example: maxima or minima, transformations of the indicators to the range $0-1$, percentile truncate at $10 \%$ and $90 \%$. For the combination of indicators, two methods can be applied, the weighted average method and the weighted product method:

$$
\text { Score }=\left(\mathrm{A}_{1}^{\beta 1} * \mathrm{~A}_{2}^{\beta 2} * \ldots * \mathrm{~A}_{\mathrm{n}}^{\beta \mathrm{n}}\right)^{\wedge}\left(1 /\left(\beta_{1}+\beta_{2}+\ldots+\beta_{\mathrm{n}}\right)\right.
$$

The result can be presented as a potential production map for the whole world or for a specific region/country. For illustrative purposes, the potential to produce tomatoes in Brazil is shown in Fig. 1; which takes into account a few dozen indicators combined by using the weighted product method (Fig. 1).

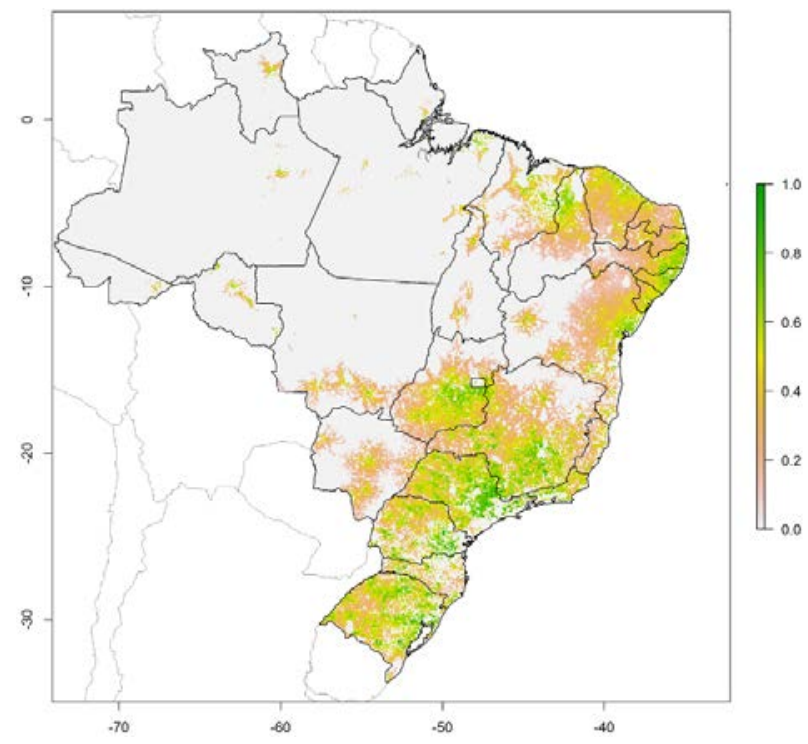

Figure 1: Example of a presentation of the result produced by Global-Detector (case "Potential for tomato production (worldwide))" for Brazil; green is good potential). 
Global-Detector is extended towards the tool Global Metropolitan Detector in which data on food security risks and opportunities are analysed for metropolitan areas with more than 600.000 inhabitants ( 850 cities in total in order to reduce the number of cities and to limit to metropolitan areas). Some of the aspects of Global Metropolitan Detector are described in more detail below.

\subsection{Defining metropolitan areas of 850 largest cities}

Metropolitan areas around the world vary with respect to geographical circumstances, climate, infrastructure, availability of land for agriculture or recreation, etc. Many metropolitan areas are in a transition towards a more sustainable future (e.g. sustainable development goals, SDGs). Unfavourable conditions may cause difficulties in this transition, now or in the (near) future, while other factors can be advantageous for attaining sustainability. Conditions can be at the local/city level, metropolitan, national or global level. In this paper, we concentrate on the metropolitan level in order to focus on urban food security issues with respect to short supply chains and ecosystem services related to food. In order to identify the metropolitan areas, a radius is drawn around each city. The Initial value of the radius is a function of the population size. The area of a circle is $\Pi^{*} \mathrm{r} 2$. When assuming an average population density of 3000 per square $\mathrm{km}$, then the radius is $\left\{\text { Population } /\left(3000^{*} \Pi\right)\right\}^{\wedge} 0.5$. All grids within this radius are classified as either urban, intermediate or rural, taking into account thresholds for population density per square $\mathrm{km}$, as defined in [19], and travel time to cities [20] in which rural grids with low travel time are regarded as intermediate, and intermediate grids with very low travel time regarded as urban. With an iterative procedure the radius is increased stepwise until the number of rural grids is more than 50\%. The dataset from [21] is used as a reference for the cities' location.

Rural areas around these cities are assumed to supply the urban areas with food. To analyse the degree to which this is met, the concept "Food metres" [22] is used. The Food metres concept is described in more detail in the section below.

\subsection{Food Metres as a way to calculated land needed for food production}

Food metres, in this paper, is defined as the area of land in hectares to produce enough food that is demanded by 1000 people. This area depends on the country specific consumption per capita and the productivity (kg per hectare). Data from FAOSTAT [23] are used to calculate Food metres for each country. In countries with a low demand/high productivity, a much smaller area is required compared to countries with high demand/low productivity. For each specific country, the demand of food products from "FAO Food Balance" and the production per hectare derived from "FAO Crops" are combined. Different categories and aggregation levels are harmonized, e.g. consumption of "rice" and "rice oil". The procedure has been validated by a FAO data specialist from the author's organisation. Finally, products are aggregated in food categories, i.e. arable crops, vegetables and fruit.

\subsection{Dimensions and indicators of Global Metropolitan Detector}

For each of the 850 cities, values for the indicators belonging to one of 5 dimensions related to food security are calculated by Global Metropolitan Detector. Functions mentioned above are applied. Some indicators are based on data at the country level, e.g. GDP (gross domestic product), others on grid level, i.e. the grids belonging to the metropolitan area within the radius (e.g. agricultural land). Country level data can be differentiated such that they have different values for the cities within a country, e.g. the consumption of kcal from fish (derived 
from FAO data) is assumed to be higher for cities at or near a port compared to cities situated in the countryside. Productivity (kg per hectare) is assumed to be higher in regions with better climatic conditions. Dimensions for Global Metropolitan Detector, as described below, are linked to the dimensions from the definition of food security.

I Availability: food production around the city This dimension consists of the potential area for fresh food (situated very close to the cities), area for other vegetables, fruit and nuts, and all remaining agricultural land for arable production (further away from the cities). The potential areas for fresh food and for vegetables and fruit are also assumed to be produced on existing cropland, so arable land could be converted to land for vegetables. The supply from these areas are compared with the demand ("Food Metres"): cities that meet the demand better have a higher score for availability.

IIa Accessibility: transport

The accessibility of food is better when the travel time is low, when the country has a good score for "Ease of doing business" (data from Worldbank), for a stable country ("Fragile State Index", www.fundforpeace.org) and a high percentage of urban population. Travel time, which is a measure of logistic, is considered as the most important indicator.

IIb Accessibility: affordable

High GDP and GDP development lead to a high value for this dimension. Other contributing indicators are economic activity (derived from the worldwide "Nightlight" map from NASA) and income equality (Gini coefficient).

III Utilisation: health

The consumption of healthy food and a healthy lifestyle are considered to lead to lower food risk in a situation when there is enough food. This dimension consists of the indicators healthy body mass index (BMI) (i.e. not too high, not too low), enough possibilities for urban recreation in e.g. woods (exercise), a total daily kcal intake that is neither too high nor too low, and relative much kcal from fish, vegetables, fruit and nuts.

IV Stability: Low food risks

Low food risk is assumed when the population increase of the city is low, the city lies in a suitable climate (not too low/high temperature and precipitation) with low climate risk, having a low risk of flood, and not too low BMI or total kcalintake. The risk of flood is higher when the city lies near the sea or a river in combination with high precipitation; especially when many people live at low altitude.

The 5 dimensions are combined (with equal weight) leading to an index for food security risks and opportunities. In cities with a very high score, the food is available, accessible and affordable. People have a healthy consumption and there are low food risks. The scores of the dimensions and the index are converted to 9 percentile classes with rates 1 to 9 , resulting in a mean of 5 for each dimension for the whole world. A class value higher than 5 means a better position with respect to food security (best is 9), below 5 a worse one.

\section{RESULTS: LARGEST CITIES OF THE WORLD (850) COMPARED}

The result of the calculations of Global Metropolitan Detector for the 850 cities is a table of the values of the indicators and a table of the values of the dimensions. The tables can be analysed and used for comparison. An example is shown in Table 1. For six cities, which are unordered, the dimensions can be compared. Accra for example, has the lowest rates for "Accessible". "Health" rate for Addis Ababa is not only the lowest of these 6 cities but also belongs to the group of the lowest percentage class (i.e. "1") of the whole world. 
Table 1: Example of rates (range 1 to 9) for the 5 dimensions for 6 cities.

$\begin{array}{llccccc}\text { Country } & \text { City } & \text { Available } & \text { Accessible } & \text { Affordable } & \text { Health } & \text { NoFoodRisk } \\ \text { Ethiopia } & \text { Addis Ababa } & 2 & 3 & 3 & 1 & 3 \\ \text { Nigeria } & \text { Lagos } & 2 & 4 & 2 & 3 & 1 \\ \text { Viet Nam } & \text { Hà Noi } & 5 & 8 & 4 & 2 & 1 \\ \text { Ghana } & \text { Accra } & 2 & 8 & 2 & 7 & 3 \\ \text { Uganda } & \text { Kampala } & 3 & 5 & 2 & 2 & 1 \\ \text { Bangladesh } & \text { Dhaka } & 3 & 7 & 4 & 2 & 1\end{array}$

Maps can be generated with Global Metropolitan Detector for each dimension of the final index, not only for the whole world but also for a specified region. Fig. 2 shows the map for the dimension "No food risk" for Europe and the northern part of Africa. Each map has 9 colours, ranging from dark red (rate 1, i.e. very unfavourable) to dark green (rate 9, very favourable). Fig. 3 shows the map for the final index (i.e. the combination of all dimensions) for East-Asia and surrounding regions. Such maps can be created for other parts of the world or for a smaller region, e.g. for Mexico and surroundings (Fig. 4), in order to have a better geographic orientation.

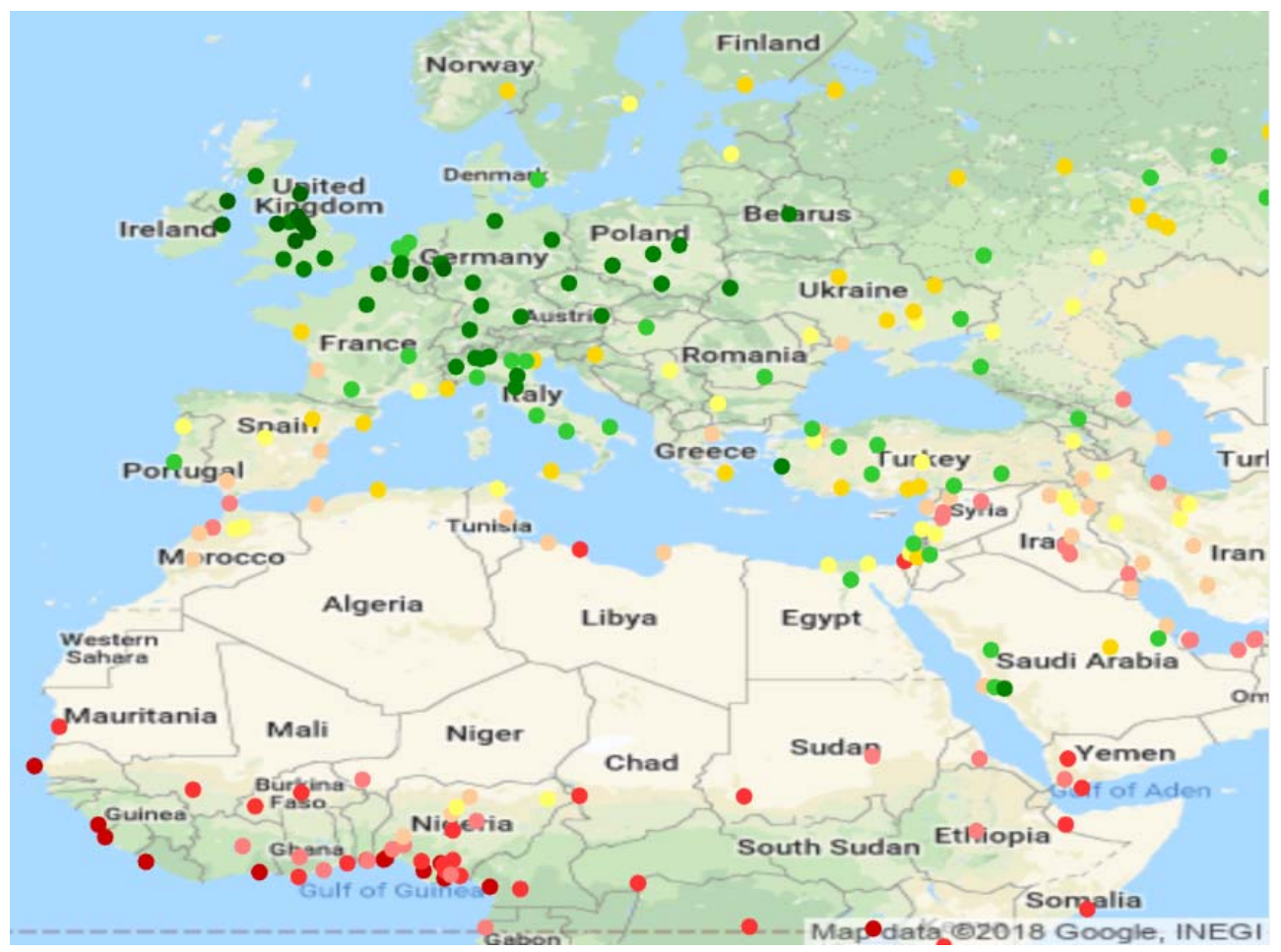

Figure 2: Ratings for the dimension "No food risk" for Europe and northern part of Africa, ranging from 1 (very high risk, dark red) to 9 (very low risk, dark green). 


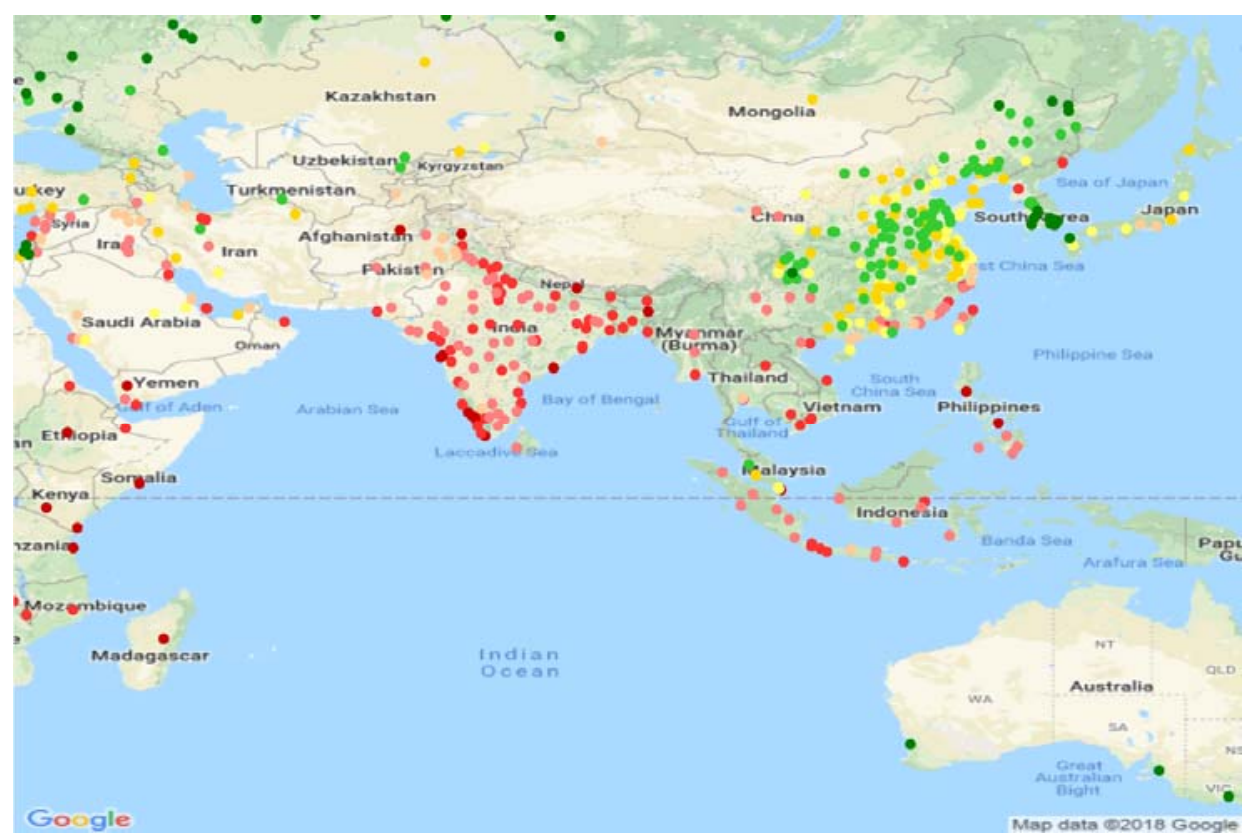

Figure 3: Ratings for the combined final index for East-Asia ranging from 1 (very low, dark red) to 9 (very high or favourable, dark green).

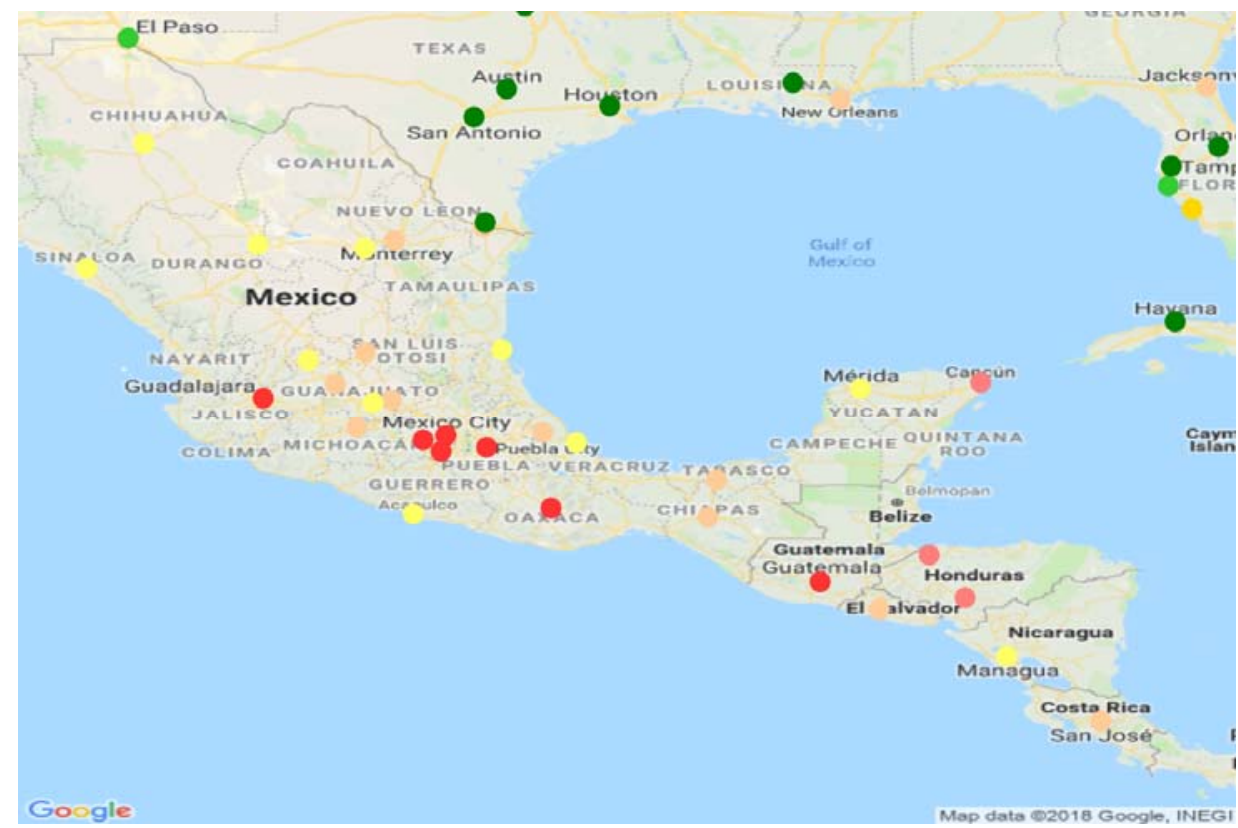

Figure 4: Ratings for the combined final index for Mexico ranging from 1 (very low, dark red) to 9 (very high or favourable, dark green). 
Cities can be compared based on the values and ratings in the tables or from the colours on the maps. Within a country, cities have their specific geographic location, so regional patterns of urban food security can be identified. Climatic conditions, potential areas for food production or infrastructure can be better in one region compared to another region. For example, in China (Fig. 3), there are cities with a good urban food security situation (relative to all cities in the world, green dots) and cities with a bad situation (red dots), even though country-level indicators like GDP and stability are assumed to be the same.

\section{CONCLUDING REMARKS AND DISCUSSION}

Global Metropolitan Detector aims to analyse the situation of urban food security risks and opportunities for the 850 largest cities in the world, thus allowing one to identify regional food security patterns within a country or region. It does so by applying a straightforward methodology to combine as many food security dimensions at the most detailed level as possible. Public available data are used as input for the tool, with the tool thus being restricted to the availability of these data. Although detailed data for cities can be found (e.g. on socioeconomic and cultural factors), such detailed data are often restricted to one or a limited number of cities, while the tool requires data to have worldwide coverage. Because of lack of worldwide data for the cities, the tool uses some indicators on country level (e.g. GDP) and assumes that these are the same for all cities within a country. Despite these country level indicators, a large degree of variation between cities within a country can sometimes be observed, due to the grid level indicators of Global-Detector (e.g. China in Fig. 3). However, the tool is at the moment not able to capture the large variations within a city, e.g. districts with high and with low income. Should data be available at the neighbourhood-level, the tool can be improved in order to account for these variations in urban food security.

The results obtained by the tool are, however, very dependent on certain assumptions regarding geographic factors. For example, the choice of the radius around the city can have a large influence on the result, particularly the supply of food. A larger radius would be beneficial for the supply/demand balance, especially for cities whose croplands are further away. It was decided to use the urban classification of Dijkstra and Poelman [19] and a threshold of more than 50\% rural grids. Results would differ if other criteria were applied, especially for the dimension "Availability".

When interpreting final results, it is important to be aware that some indicators may be statistically correlated. For example, GDP (used in "Affordable") is correlated to BMI (used in "Health" and "Low food risk"); the indicators "Ease of doing business" and "Stability" of countries are, in general, also worse in countries with low GDP; the share of vegetables and fruit in the diet is higher in countries with low GDP and BMI. Indicators that are correlated should, in principle, be excluded from the construction of a composite indicator [24]. However, omitting these indicators would lead to a poor representation of some of the dimensions of urban food security. There is therefore a trade-off between being strict with the statistical soundness and keeping the conceptual coherence of the indicator [24]. Further research is needed for this, as the project is ongoing.

The results of the analysis may be useful for policy makers and staff of non-governmental organizations (NGO) who are especially engaged in food security issues. For cities with a bad food situation (red dots), scores of the indicators and dimensions can be analysed to find the causes of that bad situation and compare these with other cities. The maps can be useful for a quick overview of the situation and for communication purposes. We are aware that the use of limited data and choices for radius, parameters and calculation procedures make the results only indicative, but it may be a good starting point for detailed data acquisition and 
successive analyses. The outcome of Global Metropolitan Detector should be regarded as a direction and an aid for further analysis.

\section{REFERENCES}

[1] FAO, Rome Declaration and Plan of Action. World Food Summit, 1996. http://www.fao.org/docrep/003/w3613e/w3613e00.HTM.

[2] FAO, The state of food insecurity in the world 2001. Italy: Food and Agriculture Organization, 2002. http://www.fao.org/docrep/003/y1500e/y1500e00.htm.

[3] Schmidhuber, J. \& Tubiello, F.N., Global food security under climate change. Proceedings of the National Academy of Sciences, 104(50), pp. 19703-19708, 2007.

[4] Stamoulis, K. \& Zezza, A., A conceptual framework for national agricultural, rural development, and food security strategies and policies. ESA Working Paper No. 03 17. Rome: Agricultural and Development Economics Division, Food and Agriculture Organization, 2003. http://www.fao.org/docrep/007/ae050e/ae050e00.htm.

[5] Achterbosch, T., Van Berkum, T.J. \& Meijerink, G.W., Cash crops and food security; Contributions to income, livelihood risk and agricultural innovation. LEI Report 20142015. Wageningen, the Netherlands: LEI Wageningen UR, 2014.

[6] EIUL, Global Food Security Index 2017: Measuring food security and the impact of resource risks. London, UK: The Economist Intelligence Unit; 2017.

[7] OECD/FAO/UNCDF, Adopting a Territorial Approach to Food Security and Nutrition Policy. OECD Publishing; 2016. http://www.oecd-ilibrary.org/urban-rural-andregional-development/adopting-a-territorial-approach-to-food-security-and-nutritionpolicy_9789264257108-en.

[8] Tacoli, C. \& Vorley, B., Reframing the debate on urbanisation, rural transformation and food security. London, UK: International Institute for Environment and Development, 2015. http://pubs.iied.org/17281IIED/.

[9] Crush, J.S. \& Frayne, G.B., Urban food insecurity and the new international food security agenda. Development Southern Africa, 28(4), pp. 527-544, 2011.

[10] Cohen, M.J. \& Garrett, J.L., The food price crisis and urban food (in)security. Urbanization and emerging population issues-2, Human Settlements Working Paper Series. London, UK: International Institute for Environment and Development, Population and Development Branch United Nations Population Fund. http://journals.sagepub.com/doi/10.1177/0956247810380375, 2010.

[11] Zezza, A., Davis, B., Azzarri, C., Covarrubias, K., Tasciotti, L. \& Anriquez, G., The impact of rising food prices on the poor. ESA Working Paper No. 08-07. Rome, Italy: Agricultural Development Economics Division, Food and Agriculture Organization, 2008. http://www.fao.org/family-farming/detail/en/c/283216/.

[12] Ruel, M.T. \& Garrett, J.L., Features of urban food and nutrition security and considerations for successful urban programming. eJADE: Electronic Journal of Agricultural and Development Economics, 1(2), 2004. https://ideas.repec.org/a/ ags/ejadef/12002.html.

[13] UNDESA, World Urbanization Prospects: The 2014 Revision. Report No.: ST/ESA/SER.A/366. New York, USA: United Nations, Department of Economic and Social Affairs, Population Division, 2015.

[14] Tacoli, C., Bukhari, B. \& Fisher, S., Urban poverty, food security and climate change. Human Settlements Working Paper No.37, Rural-Urban Interactions and Livelihood Strategies. London, UK: International Institute for Environment and Development; 2013. http://pubs.iied.org/10623IIED/. 
[15] Maxwell, D., The political economy of urban food security in sub-Saharan Africa. World Development, 27(11), pp. 1939-1953, 1999.

[16] Ravallion, M., Chen, S. \& Sangraula, P., New evidence on the urbanization of global poverty. Population and Development Review, 33(4), pp. 667-701, 2007.

[17] Sonnino, R., The new geography of food security: exploring the potential of urban food strategies. The Geographical Journal, 182(2), pp. 190-200, 2016.

[18] Hennen, W.H.G.J., Daane, P.A. \& Van Duijvendijk, K., Global-Detector; GIS- and Knowledge-based tool for a global detection of the potential for production, supply and demand. Proceedings of the 3rd International Conference on Geographical Information Systems Theory, Applications and Management. Porto (Portugal), pp. 161-168, 2017. https://www.wur.nl/en/Publication-details.htm?publicationId= publication-way-353333353634.

[19] Dijkstra, L. \& Poelman, H., A harmonised definition of cities and rural areas: the new degree of urbanisation. Report No.: WP 01/2014, Regional Working Paper 2014, Luxembourg: European Commission. 2014.

[20] Weiss, D.J. et al., A global map of travel time to cities to assess inequalities in accessibility in 2015. Nature, 553(7688), pp. 333-336, 2018.

[21] United Nations Population Division; United Nations Department of Economic and Social Affairs. Online. http://www.un.org/en/development/desa/population/ publications/database/index.shtml. Accessed on: 21 Dec. 2016.

[22] Wascher, D.M. et al., FOODMETRES - Metropolitan food planning connecting the local with the global. Urban Agriculture Magazine, 29, pp. 41-44, 2015.

[23] FAOSTAT, Food and Agriculture Organization. Online. http://www.fao.org/ faostat/en/\#home. Accessed on: 21 Nov. 2016.

[24] OECD/JRC, Handbook on Constructing Composite Indicators: methodology and user guide, OECD Publishing: Paris, 2008. http://www.oecd.org/sdd/42495745.pdf. 